\title{
North-Holland ANNOUNCES:
}

\section{PHYSICA D: Nonlinear Phenomena}

\section{Editors:}

\section{H. Flaschka}

University of Arizona, Department of Mathematics, Tucson, Arizona 85721

\section{J. Ford}

Georgia Institute of Technology, School of Physics, Atlanta, Georgla 30332

\section{A.C. Newel}

Clarkson College of Technology,

Department of Mathematics and Computer Science, Potsdam, New York, 13676

\section{A. Scott}

University of Wisconsin,

Department of Electrical and Computer Engineering,

Madison, Wisconsin 53706

\section{Aims and Scope:}

- This new section of Physica is designed with the aim of providing a common forum for scientists interested in exploring the role of nonlinearity in natural phenomena. It will contain:

- Communications of original research, conforming to the general standards described below.

- Invited or contributed surveys accessible to readers with diverse backgrounds.

- Announcements and summaries of meetings, recommendations of books or review papers, etc.

In order to give some focus to the first few issues, the editors intend to stress certain areas in which the importance of nonlinearity is particularly apparent: numerical analysis and applied mathematics, hydrodynamics, plasma physics, statistical physics, solid state physics, celestial mechanics, quantum field theory, biological or chemical reaction-diffusion systems. The principal aim is to publish reports of experiments, techniques, and ideas which - although they may be derived and explained in the context of a particular field - advance the understanding of nonlinear phe. nomena in general.

\section{Advisory Board:}

D.J. Benney (U.S.A.), A. Bers (U.S.A.), F. Calogero (ltaly), C. Conley (U.S.A.), P. Fife (U.S.A.), P. Goddard (England), H. Haken (Germany), M. Hénon (France), A. Jackson (U.S.A.), A.N. Kaufman (U.S.A.), J. KrumhansI (U.S.A.), M. Kruskal (U.S.A.), J. Lebowitz (U.S.A.), J. Nagumo (Japan), S. Rice (U.S.A.), M. Sato (Japan), L. Segel (Israel), Y. Sinai (U.S.S.R.), G. Strang (U.S.A.), R. Temam (France), M. Toda (Japan), C. Tracy (U.S.A.), S. Trullinger (U.S.A.), N.J. Zabusky (U.S.A.), V.E. Zakharov (U.S.S.R.)

\section{Contents First Issue:}

Solitons in Condensed Matter: A Paradigm (A.R. Bishop, J.A. Krumhansl, S.E. Trullinger)

The Inverse Scattering Solution for the Full Three Dimensional Three-Wave Resonant Interaction (D.J. Kaup) Evidence that Random Behaviour is Generic for Nonlinear Differential Equations (S.A. Orszag, J.B. McLaughlin) Density Matrix of Inpenetrable Bose Gas and the Fifth Painlevé Transcendent (M.Jimbo, T. Miwa, Y. Mori, M. Sato) Degenerative Dispersion Laws, Motion Invariants and Kinetic Equations (V.E. Zakharov, E.I. Schulman)

The Second Soliton Workshop - Jadwisin 1979: a short summary by $A$. Sym

\section{Forthcoming Articles:}

Instantons and Magnetic Monopoles in Yang-Mills Gauge Theories (M.K. Prasad)

Nearly Linear Mappings and their Applications

F. M. (sraelev)

Classical Hamiltonian Perturbation Theory Without Secular Terms or Small Denominators (H. Abarbanel)

Symbolic Dynamics and Relaxation Oscillations (J. Guckenheimer)

Different Ways to Turbulence in Dissipative Dynamical Systems (P. Manneville, Y. Pomeau)

Fluid Dynamical Form of the Linear and Nonlinear Schrödinger Equations (E.A. Spiegel)

Starting in the second issue a new section: Non. linear Science Abstracts

\section{Call for papers:}

In accordance with the goals of the Journal, both research papers and survey papers are invited. All contributions should be sent to any one of the four editors. A research paper should deal with an aspect of nonlinearity of potential relevance to diverse areas. Use of specialized language should be minimized so that readers can evaluate the applicability of the idea to other fields. Survey papers dealing with the role of nonlinearity in problems of general scientific interest or with techniques of value in different fields are particularly welcome. A honorarium is provided for each survey article upon acceptance. A prospective author of a survey article should first contact the editors with a proposal.

\section{Subscription Information:}

1980: Volume 1 (1 volume in 4 issues) Subscription price for 1980: US \$98.00/Dfl. 191.00 including postage and handling.

Combined Subscription price for 1980 : Physica A (Vols. 100-104), B + C(Vols. 100 and 101) and $D$ : US $\$ 660.50 / D f l .1288 .00$ including postage and handling.

Free specimen copies are avallable upon request. 
Continued from back cover

Wave propagation in a temperate multi-species plasma around the ion cyclotron frequency range

G. JANZEN

Exact electron-acoustic solitary waves

B. BUTI, M. MOHAN AND P. K. SHUKLA

Self-consistent profile modification in the underdense region of laser-produced plasmas

J. R. SANMARTÍN AND J. L. MONTAÑES

On the validity of a hydrodynamic description of Laser-driven fusion

D. N. LOWY AND H. J. KREUZER 


\section{JOURNAL OF PLASMA PHYSICS}

\section{Volume 23 Part 2 April 1980}

\section{CONTENTS}

Derivation of CGL theory with finite Larmor radius corrections

R. K. CHHAJLANI AND S. C. BHAND

Quasi-linear approach to the propagation of Bernstein waves in an inhomogeneous plasma.

A. AIROLDI CRESCENTINI AND A. OREFICE

A fluid description of plasma double-layers

J. S. LEVINE AND F. W. CRAWFORD

Instability of lower-hybrid waves in collisional plasmas with a field-aligned current

KAI FONG LEE

A relativistically covariant formulation in the theory of plasma stability

I. MERCHES

Effective collision frequency and electron temperature in a weakly ionized argon plasma

C. P. SCHNEIDER

Statistical thermodynamics of temperature anisotropy driven Weibel instabilities

DON S. LEMONSAND D. WINSKE

Dual propagation and absorption in a warm plasma half-space EDWIN J. DORCHAK JR AND RICHARD L. LIBOFF

Waves in magnetoplasma with a stochastic magnetic field

Y. S. PRAHALAD AND M. L. MITTAL

Continued on inside back cover

(C) Cambridge University Press 1980

\section{CAMBRIDGE UNIVERSITY PRESS}

THE PITT BUILDING, TRUMPINGTON STREET, CAMBRIDGE CB2 1RP 32 EAST 57TH STREET, NEW YORK, N.Y. 10022

Printed in Great Britain at the University Press, Cambridge 